\title{
Mixed Services and Mediated Deservingness: Access to Housing for Migrants in Greece
}

\section{Katerina GIyniadaki}

European Institute, London School of Economics

E-mail: a.glyniadaki@/se.ac.uk

As the delivery of social services is increasingly carried out by contractors, it is no longer state officials alone who determine clients' 'deservingness'. This article draws attention to the interrelated notions of mixed services and mediated deservingness as they apply in the context of migrants' access to housing in Athens, Greece, during the so-called 'migration crisis' of 2015-2017. It argues that non-state actors essentially act as intermediaries between the state and the migrant clients, making their own judgements on the migrants' deservingness and using their discretionary power accordingly. The findings reveal distinct discretionary patterns among street-level actors who represent migrants, depending on how each interprets the notion of 'vulnerability' with regard to gender and age. Although these actors' room for manoeuvre is framed by the policy framework and the structural conditions in which they operate, their individual normative assumptions play a critical role in shaping their discretionary behaviour towards migrants.

Keywords: Deservingness, street-level bureaucracy, migrants, housing.

\section{Introduction}

The so-called 'European migration crisis' of 2015-2017 was a particularly challenging period for the southern EU member states which represented the gates to Europe for the majority of incoming asylum seekers. However, although much of the scholarly debate has focused on the regime of 'fortress Europe' as a bordering practice, less attention has been dedicated to the everyday practices that enable or inhibit the migrants' access to services which are fundamental to their well-being and integration (Lamont, 2014; Eule et al., 2018, see also Psimmenos and Kassimati, 2003; Cabot, 2014). To address this gap, this article focuses on the city of Athens, Greece, and examines the migrants' access to housing. It also investigates the de facto access asylum seekers and refugees have to housing opportunities and how the discretionary behaviour of those at the street level of service delivery facilitates or impedes this access.

Drawing from the theory of street-level bureaucracy (Lipsky, 1980) and an analysis of qualitative interviews with street-level actors in the field of migrant service provision in Athens, this article highlights the relationship between two key notions: mixed services and mediated deservingness. The former refers to the amalgam of state and non-state actors who interact and cooperate while delivering services, while the latter suggests that the migrants' access to services is mediated by various local street-level actors who exercise their individual judgement on the deservingness of their clients. Through an examination of these interrelated notions, this article posits that we can better understand 
how the increasing diversification of street-level actors influences the process of service delivery for migrant clients.

Expanding further on the concept of 'deservingness', this research finds that some migrants (referring here to asylum seekers and refugees) are indeed seen and treated as being more worthy of receiving access to housing than others. This transpires through the underlying normative basis of the policies themselves as well as through the street-level actors' interpretations of these policies. Either way, some invisible dividing lines determine which migrants get access to housing and which do not. In this informal selection process, this article shows, the role of the migrant representatives, or 'intermediaries', who operate at the interface between the state and the migrant clients is of critical importance. Individual understandings of 'vulnerability' in relation to gender and age permeate discretionary practices at the street level, ultimately translating into informal bordering practices.

The remainder of this article is divided into four sections. The first section situates this research within the relevant literature and offers a theoretical lens through which the topic at hand can be better understood. The next section describes the research methods used in this study as well as the social and policy context of the case under examination. Then, the empirical findings are presented and discussed. The article concludes with a short discussion of its contributions and their broader implications.

\section{Delivery, deservingness and discretion}

\section{Mixed social services}

As Michael Lipsky (1980) has long pointed out, public service employees who have direct contact with clients almost always have some room for discretion when implementing policy. Depending on how they use this discretion, they shape policy outcomes. In this sense, these 'street-level bureaucrats', as Lipsky called them, effectively operate as policymakers. Today's body of street-level bureaucrats, however, does not consist merely of public servants, as it is much more complex and diverse.

Since the conception of the term 'street-level bureaucracy' (Lipsky, 1980), front-line service delivery has changed in significant ways. Largely a consequence of the New Public Management trend that arose in the 1980s and its emphasis on a 'businesslike' approach to governance, today much of public service delivery is no longer conducted by public agencies. Rather, it is carried out by private companies contracted by the state, or non-governmental organisations, or 'hybrids' of different organisational types (Smith and Lipsky, 1993; Maynard-Moody and Portillo, 2010; Brodkin, 2011). As a result, the individuals who enact policy at the street level may be public servants, private service employees or members of the civil society.

Yet, despite the increased prevalence of new types of street-level actors, the existing empirical studies that account for multiple diverse actors at once are few and limited in scope (e.g. Nisbet, 2015; Humphris, 2018). Besides the fact that countries at the borders of the EU have been generally under-studied from this theoretical perspective, a critical aspect that has been overlooked is the role of civil society members, paid or unpaid, as de facto policy implementers. When it comes to social services for migrants in particular, the role played by those who assist the migrants' interactions with the state authorities is of fundamental value. Think, for instance, of a volunteer at an NGO who assists migrants in obtaining access to housing. By carefully guiding them to follow the bureaucratic 
procedures (e.g. collecting and submitting the required paperwork), this volunteer is essentially helping to implement policy.

It is the role of these 'intermediaries' between the state and the clients that this article is seeking to highlight. As the subsequent section will illustrate, in the case of Greece, the so-called 'migration crisis' of 2015-2017 led to a steep rise in the involvement of such intermediaries, affiliated with a diverse range of civil society organisations and groups (Rozakou, 2017; Kalogeraki, 2020). At the same time, the sheer volume of migrant newcomers exposed the weaknesses of the existing bureaucratic system of governance and the 'grey zones' of the relevant migration policies (Cabot, 2014). In the face of unprecedented implementation problems and without existing suitable solutions, the role of these intermediaries became critical in relation to meeting the migrants' needs. In effect, these intermediaries became a new kind of 'street-level bureaucrats' or, in Lipsky's words, policymakers.

\section{Mediated deservingness}

In the literature on street-level bureaucracy, the interactions between bureaucrats and clients take centre stage. One prominent view in this direction suggests that the bureaucrats' discretionary behaviour is largely a result of normative choices, depending on their judgements regarding their clients' deservingness (Maynard-Moody and Musheno, 2003; Jilke and Tummers, 2018). In short, the more 'worthy' the clients appear to be in the eyes of bureaucrats, the more likely it is that the bureaucrats will make decisions in the clients' favour.

In light of the new reality of mixed social services, and given the language barriers migrants usually face, the state-migrant client interactions are often not direct but mediated by individuals working in the third sector. Accordingly, there is also the phenomenon of what I call here 'mediated deservingness'. By using this term, I suggest that individual judgements of a clients' deservingness continue to be of major relevance when the service receivers are migrants, but the determination of this deservingness is now a multistep process. That is, a migrant's experience during a particular interaction with a state employee is not merely contingent upon the judgement of a single bureaucrat, but rather it depends on the judgements of the various and diverse actors who mediate this state-client interaction.

When it comes to migrants' access to services in Greece, the judgement of those acting as 'migrant representatives' is key. Whether officially assigned professionals (e.g. caseworkers) or independent volunteers (e.g. interpreters), their discretionary judgement on the migrants' deservingness will determine whether they dedicate more or less effort into 'pushing' each migrant's case (see below). The individual judgements of these intermediaries will then influence the judgements of civil servants who represent the state authorities, leading to a 'chain' of discretionary decisions regarding the migrants' access to services. In this sense, the migrant clients' deservingness is almost always mediated.

\section{Multi-level discretion}

Following on from the above discussion, it is worth investigating how the intermediaries' judgement of the migrant clients' deservingness leads to distinct discretionary practices on the ground, granting services to some clients but not to others. To pursue this endeavour, this article examines the interaction between two avenues through which notions of deservingness infuse the daily routines of those working at the front lines of social service delivery. 
One of these avenues concerns the norms that the policies themselves convey, determining that some types of potential service receivers are more deserving of access to certain services than others (Chauvin and Garcés-Mascareñas, 2014; Lamont, 2014; Willen and Cook, 2016). Existing research has shown, for instance, that if a particular population group is seen by policymakers as responsible for the unfortunate situation they are in (e.g. unemployment), the candidates are less likely to receive benefits. By contrast, if this group is seen as unable to control the circumstances they are in (e.g. illness), the candidates are more likely to receive benefits (Jensen and Bang Petersen, 2017). Policies relating to migrants' access to housing are thus expected to follow similar trends.

On top of the normative assumptions of policies, the policy implementers' individually held norms or biases also infuse policy practice, since they have to interpret policy before they enact it. Norms related to gender (e.g. Alpes and Spire, 2014), race (e.g. Epp et al., 2014) and class (e.g. Dubois, 2010) represent just a few prominent examples of this proposition. Returning to Lipsky's (1980) argument, street-level bureaucrats almost always have some room for discretion when completing their assigned tasks, whether due to policy gaps and contradictions, a shortage of resources, or any other reason. It is through the use of this discretion that individual understandings of the target group's deservingness surface and manifest as daily practices.

Therefore, the discretionary behaviour of those at the front lines of social service delivery represents a function of the interaction between the implicit normative assumptions of the policy at stake and the individuals' own interpretations of it. Inevitably, these street-level actors operate within the legal limits of a particular policy framework and within the structural constraints of a particular country and its economy. Since these conditions are relatively obvious and stable over time, what varies and is worth investigating further is the human response to them. Accordingly, the following section provides some brief contextual information on the issue of housing for migrants in Greece, while the subsequent section focuses on the discretionary behaviour of street-level actors and their assumptions regarding migrants' deservingness.

\section{Methods and context}

This study is part of a $\mathrm{PhD}$ research project which examined the practice of different migration policies in Greece during the so-called 'migration crisis' of 2015-2017. The research approach involved extensive qualitative interviews with street-level actors from diverse backgrounds and, to a lesser extent, direct observations (at their workplaces). For the purposes of this article, the interview data analysed came from thirty-seven street-level actors involved in the provision of housing for migrants, some with relevant professional qualifications (social workers, psychologists, etc.) and others without (administrative employees, volunteers, etc.). The affiliations of these actors varied; some worked for public service agencies, others for international organisations, others for international or local NGOs, and yet others were volunteers or activists with a long-term engagement (minimum of six months).

These interviews were conducted in accordance with the Research Ethics Policy of the London School of Economics and they were completed during several visits to Athens between December 2015 and October 2018. They had a semi-structured framework, based on the use of an interview guide with a set of open-ended questions. The language spoken was Greek and the interviews were audio-recorded with the participants' consent. 
The audio was then transcribed verbatim and analysed thematically using the qualitative analysis software NVivo. Although the theoretical discussion of this article precedes the presentation of its empirical findings, the process between data collection and analysis has occurred iteratively.

With regard to the Greek context, it is worth noting that the civil society in Greece had been relatively weak prior to 2010, but the Greek economic crisis functioned as a catalyst for its growth (Simiti, 2017). To cover the gap between a nearly dismantled welfare state and a rising demand for services, the number of 'social' grocery stores, soup kitchens and health clinics rose dramatically. These arrangements then proved very helpful in supporting the sudden influx of migrant newcomers in the subsequent years. However, given the two co-occurring humanitarian crises (economic and migration), the most significant proportion of material and expert support came from abroad. The EU and the United Nations High Commissioner for Refugees (UNHCR) were the two main sponsors that assisted Greece's migration management, while international NGOs of various sizes also played a key role (European Commission, 2019).

Along with the rise of the formal section of the civil society, local or international, the 2015-2017 'migration crisis' was also met by unprecedented grassroots mobilisation. Employing the Greek notion of 'philoxenia', or hospitality, many locals gave a warm welcome to migrants, at least in the early stages of the crisis. The slow and inflexible state mechanisms that left asylum seekers without water, food or accommodation for days at a time 'invited' local citizens to assume responsibility and give a hand to those in need. In time, the most active of these citizens - mostly supporters of leftist or anarchist ideologies took on larger projects, such as running housing squats for migrants. In a paradoxical way, Athenian groups of activists with anti-state ideologies found themselves carrying out part of the work of the state, often through illegal means, while the government practically supported these informal efforts by turning a blind eye.

Before presenting and discussing the findings of this research, it is important to define its scope. A migrant in search of housing in Greece may have been someone who just arrived irregularly (mainly from Syria, Afghanistan or Iraq) and who was planning to seek asylum, or someone who was in transit with the intention of reaching another EU member state. It could have been a registered asylum seeker or an officially recognised refugee. As this type of distinction is not directly relevant to this research, the umbrella term 'migrant' is deemed preferable. Moreover, although housing remained a contested topic for the years that followed, this research focuses solely on the 2015-2017 period, when these interviews took place.

\section{Housing and deservingness in times of scarcity}

According to EU Regulation No. 604/2013, EU member states are obliged to offer 'adequate reception conditions' to asylum seekers. Yet, during the 'crisis' period, securing access to housing constituted a particularly challenging task for migrants in Athens, as the increasing demand for services greatly outweighed the already inadequate conditions ${ }^{1}$. Indicatively, one in eight still did not have formal access to housing by August 2017 (Kasimati and Panagiotopoulou, 2018). As Greece had not traditionally been a host migration country, it had too few housing structures in place for migrants and limited relevant policies and know-how. In the face of an unprecedented large wave of newcomers, the Greek state's administrative response was predominantly ad hoc. Mass 
accommodation sites, or state camps, were swiftly set up on the outskirts of Athens in order to operate as temporary accommodation for asylum seekers.

In the absence of specific state policies on the housing of migrants ${ }^{2}$, EU regulations and UNHCR guidelines provided a compass for professionals in the field. As soon as asylum seekers registered for an asylum application, they would be sent to one of these camps where they would remain for a few months until their asylum application process had been completed and their individual case decided. Those who received full refugee protection would no longer need the support of the state, as they would be able to work and rent a place on their own; and those whose applications were rejected would have to leave anyway.

However, meeting 'adequate reception conditions' did not go according to the above plan and asylum seekers were often homeless for weeks at a time. At the height of the influx, there were extremely long queues for asylum registration and asylum seekers had nowhere to stay in the meantime. More importantly, the entire asylum determination process was exceedingly slow, taking several years for a final asylum decision to be made, not least because of Greece's overburdened and inefficient bureaucratic system (The Greek Ombudsman, 2017). In addition, in a country with an unemployment rate of nearly 25 per cent, officially becoming 'a refugee' did not guarantee that an individual would be able to find a job, while a rejected application practically meant even more years in limbo.

As a consequence, the state camps quickly became overcrowded, especially postMarch 2016 when the 'Balkan route' closed and the EU-Turkey agreement was signed, resulting in many more migrants becoming 'stuck' in Greece. Nonetheless, despite the poor living conditions in the camps (including the lack of warm water, too few toilets and not enough security, The Greek Ombudsman, 2017), transferring to flats did not represent a viable option for most migrants. Given the high demand for housing migrants vis-à-vis the limited tangible solutions available, there was inevitably a need to prioritise some migrants over others.

Article 22 of EU Regulation No. 604/2013 suggests that the special reception needs of those who are 'vulnerable' should be taken into account, while Article 18 states that parameters such as gender and age should be considered. Hence, in the effort to de-crowd state camps, migrants who were considered 'vulnerable' would be given priority access to private accommodation. Single mothers with underage children, for instance, would be given precedence over single childless men, while those with a physical disability or in ill health would have priority over the nondisabled and healthy. Operating within this policy framework, those in charge of transferring asylum applicants to flats had to use their professional discretion accordingly. Street-level actors who took on this task were expected to 'pick out' the most vulnerable migrants, thereby choosing who to help and who to leave behind.

This lack of structures is making you think and to prioritise things yourself. I mean, if a single man comes to me, $[\ldots]$ and he is a single man alone, without any vulnerability, I will not even do the process. I will file the application for housing as he asks me, but I know there is nowhere I can base my case to fight for him. I try to fight for those who have some vulnerability, because I have something to build [my case] on. Because, if every time you go there and you get into an argument for every single one of them who comes and asks for help, in the end [the authorities] will stop even speaking with you. (Social Worker, Municipality of Athens) 
This social worker's experience makes it clear that the limited amount of available housing in conjunction with the fuzzy notion of vulnerability meant that street-level actors who represented migrants had to 'pick their fights'. Inadvertently, the cases of migrants who were not categorised as vulnerable, neither by the UNHCR (2016) guidelines nor in the eyes of these actors, ended up receiving less attention because they were not seen as 'worth fighting for'. One should also note here that this social worker seems to position herself as a middleperson between the migrant clients and the state authorities.

On the flipside of 'picking out' the most deserving, this selection process also involved rejecting those judged as least deserving, which in fact meant those perceived as least vulnerable. Once again, the inherently vague notion of vulnerability allowed street-level actors some room for discretion when interpreting the relevant guidelines.

It depends on what the vulnerability of each asylum seeker is. If it is a woman alone with kids, you are not going to kick her out. Even if she has been fighting with her flatmate, you will find a way, transfer them to another flat, etc. But, if it is a single man, who has taken out a knife, and has hurt one of his flatmates, maybe it is easier to tell him that he has to get out. And he knows this behaviour is not allowed. He has signed a specific contract that bans that. (Caseworker, local NGO)

In this account, as with the preceding one, it appears that a common criterion for assessing a migrant's vulnerability is their gender. As noted earlier, a single mother is indeed far more likely to be vulnerable than a single childless man. Nevertheless, the words of this caseworker also convey a greater ascribed agency to the migrant man than to the migrant woman. Phrases such as 'he knows this behaviour is not allowed' and 'he has signed a specific contract' suggest that migrant men are fully responsible for their actions. Migrant women, by contrast, are more often assumed to be passive victims in need of help, a view that aligns with broader Western perceptions of non-Western women (Mohanty, 1988; Ticktin, 2017).

This idea of men being less vulnerable and more in control of their own fate was common among the civil society members interviewed, even among those who operated outside the particular policy framework. As the following segment illustrates, single men were also the first to be left out of the housing squats for migrants.

At [this squat] now, there is a space that is for common use, with a restaurant, and a space where the assembly takes place. We could have had beds in there and allow fifty more people to stay. But, this is not the point. [...] You could have some unaccompanied minors or single men there. But, no, this is not dignifying ... It is very hard, and it is difficult to admit, but this is how things need to be. (Activist, Housing Squat)

This activist is addressing one of the most frequent and difficult dilemmas in the field of social service provision: quantity versus quality. Knowing that many migrants are homeless $^{3}$, activists are tempted to use all the space they can to host as many as residents as possible. However, if there were too many residents in the same squat, the quality of life for everyone accommodated there would be compromised. For this reason, certain candidates had to be left out. The first to be left out on this occasion were single men and unaccompanied minors, nearly all teenage boys. As with the above example, migrant men were seen as less vulnerable than migrant women and therefore less deserving of help. 
This dichotomous distinction between vulnerable migrant women and agentic migrant men can be rather problematic (Turner, 2016), especially when taking account of other factors such as age. Young adults and minor boys were highly likely to be excluded from housing opportunities and they were the first to be expelled if they caused trouble. Yet, albeit being considered to be vulnerable due to their gender, their age does make them so.

The final example outlined here describes the case of a migrant teenage boy who had been repeatedly left out of different housing arrangements. Despite his young age, the fact that he was a boy meant that street-level actors saw him mostly as an active agent, responsible for his actions. Given also the limited housing availability, he had been repeatedly expelled from shelters for unaccompanied minors, having to live on the streets for months at a time. Due to his delinquent behaviour, he had also been excluded from most of the housing squats for migrants. Nonetheless, the following account comes from an activist who saw this boy as a vulnerable child, and therefore more deserving of support.

There is a fifteen-year-old minor boy living [at this squat]... He was sent to Greece by his parents, he doesn't know the reason, and I think this has affected him a lot... He was living after UNHCR, a partner facility for unaccompanied minors. He burned that place down... So, he was sent to live with us for a few months. And he is a very good boy. But he has been dealing drugs from a very young age... It is the only way he knows how to take care of himself. He's never been to school... There are quite a lot of [activists] who are not sympathetic. Like, 'he is dealing drugs, he is bad, he should go'... But I am more sympathetic because I understand what this boy has been through. If he's never had a parent there to tell him 'don't do this, this is bad-do this, this is better', and he's been on the streets for most of his life, hanging around with not the greatest influences, of course he's gonna sell drugs to make money and to take care of himself.... As much as other squats would kick this boy out for dealing drugs, we are more patient, and trying to get him to understand, trying to get him to curfew, and give him some discipline at the squat... I don't see how it's gonna benefit him at all by kicking him out onto the streets... (Activist, Housing Squat)

Here, this participant describes her own understanding of the troubled boy's experiences, and therefore her own view of his deservingness, which she juxtaposes with those of other activists and civil society members. Unlike those who had been previously in charge of his care, she was able to excuse this boy's engagement with drugs because 'he's never had a parent there to tell him 'don't do this". In other words, she saw him as vulnerable because of his age, and not as an active agent able to exercise critical thinking. Framed primarily as a child, and not as a boy, this migrant is deemed deserving of access to housing.

As this section demonstrates, in times of high uncertainty, street-level actors use discretionary judgements when enacting policy, regardless of their organisational affiliation (Smith and Lipsky, 1993). In the case of migrants' access to housing in Athens, street-level actors who represent them had to make their own assessments of their clients' deservingness, combining policy guidelines with their own normative understandings of vulnerability. As illustrated above, the dichotomous distinction between agentic men and vulnerable women informed the street-level actors' judgements regarding the migrants' deservingness and, consequently, their discretionary behaviour. This manifestation of discretion echoes the findings of other scholarly work where non-Western women are seen and treated as passive, innocent and in need of 
saving (Mohanty, 1988; Ticktin, 2017), whereas migrant men are portrayed as invulnerable (Turner, 2016), if not as criminal, even when minors (see also Goff et al., 2014).

\section{Conclusion}

This article has drawn attention to the interrelated notions of mixed services and mediated deservingness as they applied in the context of migrants' access to housing in Athens, Greece, during the period 2015-2017. Through the topic of housing, it has examined how the street-level actors' judgements on the migrant clients' deservingness facilitates or inhibits the migrants' access to these services. A two-fold argument was developed. First, the rise of mixed social services has enhanced the role of non-state actors who essentially operate as intermediaries between the state and migrants, advancing their own judgements regarding the migrants' deservingness. Second, the discretionary behaviour of these actors is partly a response to the structural constraints of the policy framework and the resources available, and partly a result of their individual normative assumptions concerning who counts as a deserving migrant.

More specifically, this study has shown how the shortage of housing structures and the policy which prioritised migrants who are vulnerable constrained the migrant representatives' options for helping their clients. The representatives thus used their own normative judgements to assist those migrants they saw as most deserving and exclude those they saw as least deserving. In practice, these normative judgements had a gendered dimension, ultimately leading to discretionary practices that overlooked the vulnerability of migrant boys. This points to the need for a more intersectional approach to the study of deservingness.

Overall, this research contributes to the literature on social service delivery at the street level, and to the idea that individual discretionary strategies serve as informal bordering practices that prevent some clients from accessing essential services (Psimmenos and Kassimati, 2003; Eule et al., 2018). By examining migrants' access to housing in Athens, Greece, this article adds to existing research on how individual normative assumptions about the deservingness of clients permeate daily discretionary decisions, and subsequently shape policy outcomes (Maynard-Moody and Musheno, 2003; Jilke and Tummers, 2018), while also (re)producing social inequalities (see also Lamont, 2014). More broadly, this article suggests that by enhancing our awareness of these daily practices and their normative underpinnings, we can better understand the practice of policy and its implication for migrant service receivers.

\section{Notes}

1 In 2011, Dublin transfers to Greece from other Member States were suspended after the European Court of Human Rights and the Court of Justice of the European Union identified systemic deficiencies in the Greek asylum system.

2 Greek Law 4540/2018 later came into effect with the purpose of helping implement EU Regulation No. 604/2013.

3 'Homeless' here means either sleeping on the streets or having a place at a state camp, but often in deplorable conditions (e.g. sleeping in a small tent in the open air). 


\section{References}

Alpes, M. and Spire, A. (2014) 'Dealing with law in migration control: the powers of street-level bureaucrats at French consulates', Social and Legal Studies, 23, 2, 261-74.

Brodkin, E. Z. (2011) 'Policy work: street-level organizations under new managerialism', Journal of Public Administration Research and Theory, 21, 253-77.

Cabot, H. (2014) On the Doorstep of Europe: Asylum and Citizenship in Greece, Philadelphia: University of Pennsylvania Press.

Chauvin, S. and Garcés-Mascareñas, B. (2014) 'Becoming less illegal: deservingness frames and undocumented migrant incorporation', Sociology Compass 8, 4, 422-32.

Dubois, V. (2010) The Bureaucrat and the Poor: Encounters in French Welfare Offices, Surrey, England: Ashgate.

Epp, C. R., Maynard-Moody, S. and Haider-Markel, D. P. (2014) Pulled Over: How Police Stops Define Race and Citizenship, Chicago, IL: University of Chicago Press.

Eule, T. G., Loher, D. and Wyss, A. (2018) 'Contested control at the margins of the state', Journal of Ethnic and Migration Studies, 44, 16, 2717-29.

European Commission (2019) Managing Migration EU Financial Support to Greece, April, 2019, https://ec. europa.eu/home-affairs/sites/homeaffairs/files/what-we-do/policies/european-agenda-migration/ 201904_managing-migration-eu-financial-support-to-greece_en.pdf [accessed 08.08.2020].

Goff, P. A., Jackson, M. C., Di Leone, B. A. L., Culotta, C. M. and DiTomasso, N. A. (2014) 'The essence of innocence: consequences of dehumanizing Black children', Journal of Personality and Social Psychology, 106, 4, 526-45.

Humphris, R. (2018) 'Mutating faces of the state? Austerity, migration and faith-based volunteers in a UK downscaled urban context', The Sociological Review, 67, 1, 95-110.

Jensen, C. and Bang Petersen, M. (2017) 'The deservingness heuristic and the politics of health care', American Journal of Political Science, 61, 1, 68-83.

Jilke, S. and Tummers, L. (2018) 'Which clients are deserving of help? A theoretical model and experimental test', Journal of Public Administration Research and Theory, 28, 2, 226-38.

Kalogeraki, S. (2020) 'A mixed method approach on Greek civil society organizations supporting migrants during the refugee crisis', Journal of International Migration and Integration', 21, 781-806.

Kasimati, E. and Panagiotopoulou, R. (2018) 'The migration and refugee issue in Greece during the 2015-2017 period: issues of integration and social acceptance', The Athens Jean Monnet Papers, Working Paper Nr. 10/2018 (in Greek).

Lamont, M. (2014) 'Reflections inspired by Ethnic Boundary Making. Institutions, Power, Networks by Andreas Wimmer', Ethnic and Racial Studies, 37, 5, 814-19.

Lipsky, M. (1980) Street-level Bureaucracy, Dilemmas of the Individual in Public Services, New York, NY: Russel Sage.

Maynard-Moody, S. and Musheno, M. (2003) Cops, Teachers, Counselors: Stories from the Front Lines of Public Service, Ann Arbor, MI: University of Michigan Press.

Maynard-Moody, S. and Portillo, S. (2010) 'Street-level bureaucracy theory', in R. Durant (ed.), Oxford Handbook of American Bureaucracy, Oxford, England: Oxford University Press, 252-77.

Mohanty, C. (1988) 'Under Western eyes: feminist scholarship and colonial discourses', Feminist Review, $30,1,61-88$.

Nisbet, E. (2015) 'Expanding the field of view: the role of agricultural employers in street-level immigration policy implementation', Administration and Society, 50, 8, 1097-124.

Psimmenos, I. and Kassimati, K. (2003) 'Immigration control pathways: organisational culture and work values of Greek welfare officers', Journal of Ethnic and Migration Studies, 29, 2, 337-71.

Rozakou, K. (2017) 'Solidarity \#humanitarianism: the blurred boundaries of humanitarianism in Greece', Etnofoor, 29, 2, 99-104.

Simiti, M. (2017) 'Civil society and the economy: Greek civil society during the economic crisis', Journal of Civil Society, 13, 4, 357-73. 
Smith, S. R. and Lipsky, M. (1993) Nonprofits for Hire: The Welfare State in the Age of Contracting, Cambridge, Mass: Harvard University Press.

The Greek Ombudsman (2017) Migration Flows and Refugee Protection: Administrative Challenges and Human Rights Issues, Special Report, https://www.synigoros.gr/resources/docs/greek_ombudsman_ migrants_refugees_2017_en.pdf [accessed 02.06.2020].

Ticktin, M. (2017) 'A world without innocence', American Ethnologist, 44, 4, 577-90.

Turner, L. (2016) Are Syrian Men Vulnerable Too? Gendering The Syria Refugee Response, Middle East Institute, https://www.mei.edu/publications/are-syrian-men-vulnerable-too-gendering-syria-refugeeresponse [accessed 13.06.2020].

UNHCR (2016) Vulnerability Screening Tool, https://www.unhcr.org/uk/protection/detention/57fe30b14/unhcridc-vulnerability-screening-tool-identifying-addressing-vulnerability.html [accessed 06.06.2020].

Willen, S. and Cook, J. (2016) 'Health-related deservingness', in F. Thomas (ed.), Handbook of Migration and Health, Cheltenham, UK/ Northampton, MA: Edward Elgar Publishing, 95-118. 